\title{
PATTERN OF PRESENTATION AND ORGAN INVOLVEMENT IN DENGUE FEVER AT DHAKA MEDICAL COLLEGE HOSPITAL
}

\author{
RAHMAN $\mathrm{M}^{1}$, HASAN $\mathrm{P}^{2}$, FARHEEN T ${ }^{3}$, ISLAM MK ${ }^{4}$, RASHID MHU ${ }^{5}$, HAQUE MM ${ }^{6}$, FARUQ ${ }^{7}$, \\ CHOWDHURY JA ${ }^{8}$, DATTA PK ${ }^{9}$
}

\begin{abstract}
Dengue fever first identified as 'Dhaka Fever' in 1964 \& became endemic around 2000. The most recent spreading of dengue in 2019 was also notable for change in the presenting features of the patients attributed by some to the fact that causative virus might be of different serotype. Our study aims to assess the current pattern of presentation of dengue virus infection, done in inpatient of Department of Medicine of Dhaka Medical College Hospital Dhaka. This was a crosssectional, observational, descriptive study conducted between $1^{\text {st }}$ August and $30^{\text {th }}$ September 2019. A total 70 subjects, age $>12$ years were included in this study. Among them 55 were male \& 15 were female, with a mean age of 28.33( \pm 12.15$)$ years. Comorbidities noticed in few cases such as DM (2, 2.90\%), HTN (3, 4.35\%), IHD (1,1.45\%), CKD \& COPD (1,1.45\%). The most common presentation were fever $(64,91.43 \%)$, headache $(62,88.57 \%)$ anorexia $(59,85.51 \%)$, generalised pain (51, 73.91\%), nausea (49, 71.01\%). Examination findings at admission were temperature was high but not very high, pulse were normal, both systolic \& diastolic pressure were somewhat normal, among the warning signs, severe abdominal pain (27.54\%), persistent vomiting (21.74\%), lethargy / restlessness / sudden behavioural change (21.74\%) were most common. The common haematological parameters \& routine investigation values were not deviated from expected range. As dengue is likely to continue to constitute a serious public health problem in Bangladesh, this study may help the practitioners to understand the changing pattern \& to manage patients accordingly.
\end{abstract}

Keywords: Dengue, Clinical features, Presenting features, Changes, New Serotype, Dhaka, Bangladesh.

J Dhaka Med Coll. 2019; 28(2) : 199-207

\section{Introduction}

Since its first introduction to the world during 1779-1780 in Asia ${ }^{1}$, annually, 100 million cases of dengue fever and half a million cases of DHF occur worldwide. ${ }^{2}$ The word Dengue came from the word "Denga" which was its local name in Zanzibar during 1870 epidemic. ${ }^{3}$ Although Bangladesh saw the first dengue outbreak in 1964-65, 1,3 then identified as "Dhaka Fever", it is not until the epidemic in 2000, dengue really gained the attention of medical community, mass people, media and concerned authorities. ${ }^{1,3-5}$ Since then, dengue has remained endemic in Bangladesh. ${ }^{6}$ Dhaka has always been in the most likely cluster for dengue fever. ${ }^{4}$ In Bangladesh, hospital based prevalence of immunoglobulin $\mathrm{M}$ positive dengue cases among febrile patients has been determined to

1. Dr. Motlabur Rahman, Associate Professor, Department of Medicine, Dhaka Medical College, Dhaka.

2. Dr. Pratyay Hasan, Indoor Medical Officer, Department of Medicine, Dhaka Medical College Hospital, Dhaka.

3. Dr. Tanjina Farheen, Intern Doctor, Department of Medicine, Dhaka Medical College Hospital, Dhaka.

4. Dr. Md. Khairul Islam, Junior Consultant, Department of Medicine, Dhaka Medical College Hospital, Dhaka

5. Dr. Md. Harun Ur Rashid, Indoor Medical Officer, Department of Medicine, Dhaka Medical College Hospital, Dhaka.

6. Dr. Md. Manjurul Haque, Registrar, Department of Medicine, Dhaka Medical College, Dhaka.

7. Dr. Imtiaz Faruq, Assistant Registrar, Department of Medicine, Dhaka Medical College Hospital, Dhaka.

8. Dr. Jobayer Anam Chowdhury, Thesis Part Student (MD, Cardiology), National Institute of Cardiovascular Diseases (NICVD)

9. Dr. Ponkaj Kanti Datta, Assistant Professor, Department of Medicine, Dhaka Medical College, Dhaka.

Correspondence: Dr. Motlabur Rahman, Associate Professor, Department of Medicine, Dhaka Medical College, Dhaka, Mobile: 01712040933, E-mail: rahmanmotlabur@gmail.com 
be $69 \%$ in a cross sectional study. ${ }^{7}$ In 2016 , it was reported that dengue incidence began increasing, and alarm has been raised in mainstream media too. ${ }^{8,9}$ But the real panic set in 2019 , where the spread of dengue span all over the country in a sudden surge. According to Directorate General of Health Services (DGHS), 14 people had died and 19,513 people had been affected before 1st August 2019, many of whom were children. ${ }^{10,11}$ According to Centre for Disease Control (CDC), DGHS, between January-August of 2019, total number of reported cases was 38,844 and total number of reported deaths was 29. ${ }^{12}$ Mutsuddy et.al have suggested that the climate changes after 2014, and other associated factors, such as rapid unplanned urbanization may have caused some ecological imbalances in the environment that leads to occurrence of more dengue cases in the pre-monsoon season and has also led to an explosion of chikungunya for the first time in Bangladesh in 2017. ${ }^{13}$ For a long time, dengue fever has been believed to be caused by four different serotypes (DENV-1, DENV-2, DENV-3, and DENV-4). A fifth serotype DENV-5 has been detected during screening of viral samples taken from a 37 year old farmer admitted in hospital in Sarawak state of Malaysia in the year 2007and announced in October 2013. ${ }^{14}$

Dengue is a painful disease for the patients, and has infamously been called as "break-bone fever", a name given during the first described epidemic in Philadelphia in $1780,{ }^{15}$ indicating the notoriety and severity of symptoms. ${ }^{15-17}$ The clinical features of dengue patients may consist of the following:

\section{Symptoms}

a. Fever: Typically lasting for five to seven days, with saddleback or biphasic curve manifested by a second phase fever lasting for one or two days. ${ }^{18,19}$

b. Headache

c. Retro-orbital pain

d. Muscular pain/myalgia

e. Joint pain/arthralgia

f. Marked fatigue lasting for days to weeks

g. Other symptoms ${ }^{20}$ i. Rash

ii. Gastrointestinal symptoms including nausea or vomiting

iii. Respiratory tract symptoms including cough, sore throat, and nasal congestion

2. Signs: mostly nonspecific ${ }^{21}$

a. Fever

b. Rash: The rash is typically macular or maculopapular and may be associated with pruritus.

c. Conjunctival injection

d. Pharyngeal erythema

e. Lymphadenopathy

f. Hepatomegaly

g. Petechial

h. Positive tourniquet test

3. Laboratory findings:

a. Leukopenia: Common in both adults and children ${ }^{21-23}$

b. Thrombocytopenia is noted in most patients with dengue fever. ${ }^{17}$

c. Serum aspartate transaminase (AST) levels are frequently elevated in both adults and children with dengue fever. ${ }^{18}$

Although, above mentioned clinical features or investigation findings have been known for long to be associated classically with dengue infection, the most recent experience of dengue outbreak in Bangladesh in 2019 is much different from the previous ones. The shift in the known pattern of dengue infection is seen in epidemiological context in terms of mortality and morbidity, and also in the presentation of the disease. ${ }^{13}$ Akram A reported that in 2019, the mostly detected dengue virus was of DEN 3 serotype (predominant) followed by co-detection of DEN2 \& DEN3 and DEN1 \& DEN3 (few cases), in contrast to the previous years (2013-18). ${ }^{24}$ This may also explain the fact that clinical presentations are often very much different from the previous experience. This phenomenon is noted by many leading clinicians, including Professor Dr. Md. Muzibur Rahman, Head, Department of Medicine, Dhaka Medical College, as he has pointed out in an interview to Daily Sun, ${ }^{25}$ but to this date, this phenomenon has not been properly studied or reported in any scientific literature, neither in 
Bangladesh or abroad. Thus, this study aims to assess the current pattern of presentation of dengue virus infection.

\section{Materials and methods}

General Objective:

Main objective of this study was to compare clinical features and $\mathrm{CBC}$, and other routine investigatory parameters of dengue patients.

\section{Specific Objectives:}

1. To find out the clinical features associated with dengue infection.

2. To find out the $\mathrm{CBC}$ parameter changes associated with dengue infection.

3. To find out the pattern of organ involvement associated with dengue infection.

\section{Type of study}

This was a cross-sectional, observational, descriptive study.

\section{Time of study}

The conduction of study was done between $1^{\text {st }}$ August and 30 ${ }^{\text {th }}$ September 2019.

\section{Place of study}

The study was done in the inpatient of Department of Medicine, Dhaka Medical College Hospital, Dhaka, a tertiary level Government run health care facility, acting as the ultimate referral centre. In fact, the hospital provides service to entire Bangladesh, and has to deal with a very high patient load, so a suitable place for conducting such study.

\section{Sampling method}

Consecutive, purposive sampling technique was employed. A total of 70 patients were included in this study.

\section{Inclusion Criteria}

1. Patient $>12$ years old, presenting to Department of Medicine with any of the following condition, according to operational definition:
a. Probable Dengue infection OR,
b. Dengue fever with warning signs OR,
c. Severe dengue
AND,

2. Dengue NS1 antigen was positive OR,

3. Dengue IgM was positive.

\section{Exclusion criteria}

1. Dengue IgG was positive but without Dengue NS1 antigen or, Dengue IgM positivity.

2. Unwilling to participate.

3. Patients with suspicion of bacterial fever.

4. Patients with suspicion of other virus infection.

5. Patients with significant co-morbidity which might cause fever e.g. malignancy (hepatoma) or endocrine disorders (thyrotoxicosis)

\section{Operational definition}

1. Probable dengue: ${ }^{26}$

a. Live in or travel to dengue endemic area (e.g. Dhaka),

b. Fever and two of the following criteria:
i. Nausea, vomiting
ii. Rash
iii. Aches and pains
iv. Tourniquet test positive
v. Leukopenia
vi. Any warning sign

2. Laboratory confirmed dengue: Dengue IgM or Dengue NS1 antigen was positive.

3. Dengue with warning sign: ${ }^{26}$
a. Abdominal pain or tenderness
b. Persistent vomiting
c. Clinical fluid accumulation
d. Mucosal bleed
e. Lethargy, restlessness
f. Liver enlargement $>2 \mathrm{~cm}$
g. Increases in hematocrit concurrent with rapid decrease in platelet count.

4. Severe Dengue: ${ }^{26}$

a. Severe plasma leakage leading to

i. Shock

ii. Fluid accumulation causing respiratory distress

b. Severe bleeding

c. Severe organ involvement

i. Liver ALT/AST $>=1000 \mathrm{U} / \mathrm{L}$

ii. CNS: Impaired consciousness

iii. Signs of heart or other organ involvement (e.g. raised troponin I) 


\section{Data collection process}

Data was collected by a structured closed end questionnaire with predefined set of questions. Data collection was done meticulously with detailed interviewing of the respondents.

\section{Ethics, consent and permissions}

Written informed consents were taken from all of the participants or in case of minors, consents were taken from the accompanying legal guardians/parents. In all steps of the study, all ethical aspects were strictly observed and the privacy of the data of the patients were strictly maintained.

\section{Ethical approval}

Ethical approval was taken from the Ethical Review Committee of Dhaka Medical College, Dhaka.

\section{Data analysis}

Data analysis was done in Statistical Package for Social Sciences, (SPSS, IBM Corporation, USA) version 23.0. Mostly descriptive analysis was conducted and presented with figures and tables, suitable with the purpose of this article.

\section{Results}

A total of 70 subjects, age $>12$ years, who were admitted in the Department of Medicine, Dhaka Medical College Hospital, diagnosed as dengue virus infection, were included in the study to see the pattern of presentation and organ involvement in dengue infection. The results are presented below in tables and graphs. Amon the total 70 patients, $55(78.57 \%)$ were male, and $15(21.43 \%)$ were female (Figure 1, Table 1$)$.

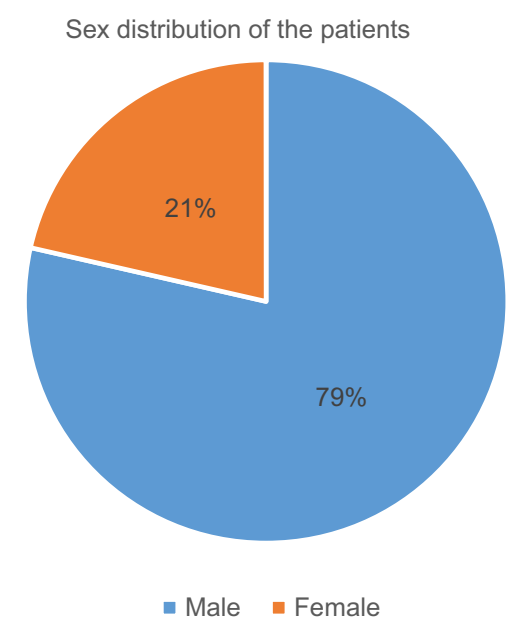

Fig.-1: Sex distribution of the patients

Most of the patients were young, with a mean age of $28.33(\mathrm{SD}, \pm 12.15)$ years and a median age of 23 (IQR, 23-35) years (Table 1). Most of the patients lived at home in urban area 59 $(86.76 \%)$ and lived in brick-built buildings 54 $(79.41 \%)$, and only a very small number of them suffered from any other significant pre-existent co-morbidity, such as, diabetes mellitus (2, $2.90 \%)$, hypertension $(3,4.35 \%)$, ischemic heart disease $(1,1.45 \%)$, chronic kidney disease (1, $1.45 \%)$ chronic obstructive pulmonary disease (1, 1.45\%) (Table 1).

Table-1

Baseline characteristics of the patients

\begin{tabular}{llccc}
\hline & & Total $(\mathrm{N})$ & Count $(\mathrm{n})$ & $\%$ \\
\hline Age in years (Median, IQR) & $23(23-35)$ & & & \\
Age in years (Mean $\pm \mathrm{SD})$ & $28.33 \pm 12.15$ & & & \\
Sex & Male & 70 & 55 & $78.57 \%$ \\
& Female & & 15 & $21.43 \%$ \\
Location of home & Urban & 68 & 59 & $86.76 \%$ \\
& Rural & & 9 & $13.24 \%$ \\
Type of household & Building & 68 & 54 & $79.41 \%$ \\
& Slum house & & 2 & $2.94 \%$ \\
& Semi paka & & 12 & $17.65 \%$ \\
Diabetes mellitus & & 69 & 2 & $2.90 \%$ \\
Hypertension & & 69 & 3 & $4.35 \%$ \\
Ischemic heart disease & & 69 & 1 & $1.45 \%$ \\
Chronic kidney disease & & 69 & 1 & $1.45 \%$ \\
Chronic obstructive pulmonary disease & & 69 & 1 & $1.45 \%$ \\
\hline
\end{tabular}

${ }^{*} \mathrm{IQR}=$ Interquartile range. $\mathrm{SD}=$ Standard deviation, $\mathrm{N}=$ total valid number of subjects upon which the observation is made, $\mathrm{n}=$ number in sub-category 
Pattern of Presentation and Organ Involvement in Dengue Fever at Dhaka Medical College Hospital Rahman M et al

Table-II

Initial presentations of the patients

\begin{tabular}{lccc}
\hline & $\begin{array}{c}\text { Total } \\
(\mathrm{N})\end{array}$ & $\begin{array}{c}\text { Count } \\
(\mathrm{n})\end{array}$ & \\
\hline Fever & 70 & 64 & $91.43 \%$ \\
Headache & 70 & 62 & $88.57 \%$ \\
Anorexia & 69 & 59 & $85.51 \%$ \\
Generalized pain & 69 & 51 & $73.91 \%$ \\
Nausea & 69 & 49 & $71.01 \%$ \\
Backache & 70 & 47 & $67.14 \%$ \\
Vomiting & 69 & 46 & $66.67 \%$ \\
Arthralgia & 70 & 45 & $64.29 \%$ \\
Fatigue & 69 & 44 & $63.77 \%$ \\
Retro orbital pain & 70 & 36 & $51.43 \%$ \\
Dyspepsia & 69 & 26 & $37.68 \%$ \\
Break-bone fever & 69 & 14 & $20.29 \%$ \\
Upper respiratory tract 69 & 14 & $20.29 \%$ \\
infection (URTI) & & & \\
symptoms & & & \\
Prostration & 68 & 13 & $19.12 \%$ \\
Lacrimation & 69 & 11 & $15.94 \%$ \\
Pharyngitis & 67 & 7 & $10.45 \%$ \\
Hyperesthesia & 68 & 6 & $8.82 \%$ \\
Depression & 68 & 6 & $8.82 \%$ \\
Scleral injection & 69 & 6 & $8.70 \%$ \\
\hline
\end{tabular}

*N= total valid number of subjects upon which the observation is made, $\mathrm{n}=$ number in sub-category
The most common presentation was fever (64, $91.43 \%)$, headache $(62,88.57 \%)$, anorexia $(59,85.51 \%)$, generalized pain $(51,73.91 \%)$ and nausea $(49,71.01 \%)$, followed by backache, vomiting, arthralgia (Table 2).

Examination findings of the patients at admission are shown in Table 3. Here it can be seen that usually temperature was high, but not very high, mean temperature in degree Fahrenheit $( \pm \mathrm{SD}): 100.74 \pm 1.70^{\circ} \mathrm{F}$, median (IQR): 101.00 (99.00-102.00) ${ }^{\circ} \mathrm{F}$. Pulse was almost normal, mean $( \pm \mathrm{SD}): 80.53 \pm 11.61$ beats/min, median (IQR): 80.00 (72.0089.00 ) beats $/ \mathrm{min}$. both systolic and diastolic BP were somewhat on the lower side of normal range. Rash was the most common examination finding $(21,30.88 \%)$ followed by bleeding spots $(12,17.14 \%)$.

Among the warning signs (Table 4), severe abdominal pain $(27.54 \%)$, persistent vomiting (21.74\%), lethargy/restlessness/sudden behavioral change $(21.74 \%)$ were the most common, followed by hematocrit rise $>20 \%$, black stool, pale, cold, clammy hands and feet.

Table-III

Examination findings of the patients

\begin{tabular}{|c|c|c|c|c|}
\hline & & Total (N) & Count (n) & $\%$ \\
\hline Pulse (beats/min) & \multicolumn{4}{|c|}{ Mean ( \pm SD): 80.53 \pm 11.61, Median (IQR): 80.00 (72.00-89.00) } \\
\hline Systolic BP (mm-Hg) & \multicolumn{4}{|c|}{ Mean $( \pm S D): 98.79 \pm 13.50$, Median (IQR): 100.00 (90.00-110.0) } \\
\hline Diastolic BP (mm-Hg) & \multicolumn{4}{|c|}{ Mean $( \pm \mathrm{SD}): 65.57 \pm 9.76$, Median $(\mathrm{IQR}): 70.00$ (60.00-70.00) } \\
\hline Temperature in Fahrenheit & \multicolumn{4}{|c|}{ Mean ( \pm SD): $100.74 \pm 1.70$, Median (IQR):101.00 (99.00-102.00) } \\
\hline Rash & & 68 & 21 & $30.88 \%$ \\
\hline Bleeding spots & & 70 & 12 & $17.14 \%$ \\
\hline Disorientation & & 69 & 1 & $1.45 \%$ \\
\hline Lymphadenopathy & & 69 & 0 & $0.00 \%$ \\
\hline Hepatomegaly & & 69 & 0 & $0.00 \%$ \\
\hline
\end{tabular}

${ }^{*} \mathrm{IQR}=$ Interquartile range. $\mathrm{SD}=\mathrm{Standard}$ deviation, $\mathrm{N}=$ total valid number of subjects upon which the observation is made, $n=$ number in sub-category 
Table-IV

Warning signs of the patients

\begin{tabular}{lccc}
\hline & Total $(\mathrm{N})$ & Count $(\mathrm{n})$ & $\%$ \\
\hline Severe abdominal pain & 69.00 & 19.00 & $27.54 \%$ \\
Persistent vomiting & 69.00 & 15.00 & $21.74 \%$ \\
Lethargy/restlessness / sudden behavioral change & 69.00 & 15.00 & $21.74 \%$ \\
Hematocrit rise $>$ 20\% & 68.00 & 13.00 & $19.12 \%$ \\
Black stool & 69.00 & 10.00 & $14.49 \%$ \\
Pale, cold, clammy hands and feet & 69.00 & 8.00 & $11.59 \%$ \\
Dark colored urine & 69.00 & 6.00 & $8.70 \%$ \\
Epistaxis & 69.00 & 5.00 & $7.25 \%$ \\
Clinical worsening during afebrile phase & 67.00 & 4.00 & $5.97 \%$ \\
Giddiness & 68.00 & 4.00 & $5.88 \%$ \\
Excessive menstruation/PV bleeding & 17.00 & 1.00 & $5.88 \%$ \\
Less urine output for 4-6 hours & 69.00 & 4.00 & $5.80 \%$ \\
Hematemesis & 69.00 & 3.00 & $4.35 \%$ \\
Hematuria & 69.00 & 1.00 & $1.45 \%$ \\
Liver enlargement $>$ 2 cm & 68.00 & 0.00 & $0.00 \%$ \\
\hline
\end{tabular}

${ }^{*} \mathrm{~N}=$ total valid number of subjects upon which the observation is made, $\mathrm{n}=$ number in sub-category

Table-V

Results obtained from investigation of the patients

\begin{tabular}{lcc}
\hline & Mean \pm SD & Median (IQR) \\
\hline Haemoglobin (g/dL) & $13.77 \pm 1.72$ & $13.60(13.15-14.75)$ \\
Total count of WBC (per cu. mm) & $5448.18 \pm 3313.21$ & $3800.00(3000.00-9000.00)$ \\
Neutrophils (per cu. mm) & 5630.00. & $5630.00(5630.00-5630.00)$ \\
Lymphocytes (per cu. mm) & 4500.00. & $4500.00(4500.00-4500.00)$ \\
Eosinophils (per cu. mm) & 230.00. & $230.00(230.00-230.00)$ \\
Hematocrit (\%) & $41.96 \pm 11.30$ & $41.00(35.65-44.05)$ \\
ESR (mm at 1st minute) & $19.09 \pm 12.69$ & $18.50(7.00-30.00)$ \\
Total count of platelets (per cu. mm) & $83879.74 \pm 70207.36$ & $60000.00(25000.00-121000.00)$ \\
Serum creatinine (mg/dL) & $1.08 \pm .38$ & $1.01(.76-1.30)$ \\
SGPT/ALT (U/L) & $239.17 \pm 645.27$ & $52.00(30.00-120.00)$ \\
SGOT/AST (U/L) & $130.00 \pm 125.23$ & $103.00(27.00-205.00)$ \\
Total serum bilirubin (mg/dL) & $2.38 \pm 3.00$ & $.70(.60-5.85)$ \\
Direct serum bilirubin (mg/dL) & 1.10. & $1.10(11.10-11.10)$ \\
\hline
\end{tabular}

* $\mathrm{SD}=$ Standard deviation, $\mathrm{IQR}=$ Interquartile range

The common haematological parameters and routine investigation values are shown in Table 4 . It is evident, that none of the values was much deviated from expected range. 


\section{Discussion}

In this study, total 70 patients were enrolled, among which 55 (78.57\%) were male, and 15 $(21.43 \%)$ were female (Figure 1, Table 1). Most of the patients were young, with a mean age of $28.33(\mathrm{SD}, \pm 12.15)$ years and a median age of 23 (IQR, 23-35) years (Table 1). This finding is also similar to that found by Manthalkar and Peerapur, who have also reported that age group of 16--30 years was more affected followed by 31-45 years. ${ }^{27}$ The sex distribution of the patients are dissimilar to Manthalkar and Peerapur, probably owing to the fact that in this study, random sampling technique was not employed. ${ }^{27}$

Most of the patients lived at home in urban area $59(86.76 \%)$ and lived in brick-built buildings $54(79.41 \%)$, and only a very small number of them suffered from any other significant preexistent co-morbidity, such as, diabetes mellitus $(2,2.90 \%)$, hypertension $(3,4.35 \%)$, ischemic heart disease $(1,1.45 \%)$, chronic kidney disease $(1,1.45 \%)$ chronic obstructive pulmonary disease $(1,1.45 \%)$ (Table 1$)$. This findings are consistent as reported by Cousins S, Akram A and others who have suggested urban areas, and especially Dhaka being at the centre of all dengue infections. ${ }^{24,28}$

In this study, the most common presentation was fever $(64,91.43 \%)$, headache $(62,88.57 \%)$, anorexia $(59,85.51 \%)$, generalized pain $(51$, $73.91 \%)$ and nausea (49, 71.01\%), followed by backache, vomiting, arthralgia (Table 2). These findings are similar to findings by Tsai et.al. and Yung et.al. ${ }^{29,30}$ Tsai et.al. have reported that patients with DENV-3 were more likely to have a malignancy $(\mathrm{p}=0.011)$, myalgia $(\mathrm{p}=$ $0.03)$, skin rash $(p<0.001)$, ascites $(p=0.04)$, and fever $(\mathrm{p}=0.003)$ than patients with DENV$2 .{ }^{29}$ Yung et.al. have reported headache, eyeache, muscle pain, joint pain, rash being the most common manifestations, similar to this study. 30

In this study, examination findings of the patients at admission are shown in Table 3. Here it can be seen that usually temperature was high, but not very high, mean temperature in degree Fahrenheit $( \pm \mathrm{SD})$ : $100.74 \pm 1.70^{\circ} \mathrm{F}$, median (IQR):101.00 (99.00-102.00) ${ }^{\circ} \mathrm{F}$. Pulse was almost normal, mean $( \pm \mathrm{SD}): 80.53 \pm 11.61$ beats/min, median (IQR): 80.00 (72.00-89.00) beats / min. both systolic and diastolic BP were somewhat on the lower side of normal range. Rash was the most common examination finding $(21,30.88 \%)$ followed by bleeding spots $(12,17.14 \%)$. The systolic BP is much lower than found in study by Yung et.al. who have reported median systolic BP between 112-116 $\mathrm{mm}-\mathrm{Hg}$ in all serotypes. ${ }^{30}$ This low level of systolic BP could possibly be attributed to many factors in this study, including, increased proportion of the sample being relatively younger, presentation at the highest referral centre requiring a great deal of journey from remote areas of country which caused pronounced dehydration, or lack of awareness of the patient parties who presented late to the hospital.

In this study, several warning signs (Table 4) such as, severe abdominal pain (27.54\%), persistent vomiting (21.74\%), lethargy/ restlessness/sudden behavioural change $(21.74 \%)$ were the most common, followed by haematocrit rise $>20 \%$, black stool, pale, cold, clammy hands and feet.

The common haematological parameters and routine investigation values are shown in Table 4. It is evident, that none of the values were much deviated from expected range. Tsai et.al. reported that patients with DENV-3 had their lowest levels of white blood cells and platelets, and peak plasma activated partial thromboplastin time (aPTT) 1 day later than patients with DENV-2. ${ }^{29}$ DENV-2 infection was associated with a higher monocyte count and more prolonged aPTT early in the clinical course. ${ }^{29}$ In this study, median platelet count was $60,000(25,000-1,21000) / \mathrm{mm}^{3}$ which is much lower than found in the study by Yung et.al. where they have found the lowest platelet count $(1,14,000 / \mathrm{mm} 3)$ in DENV-2 serotype, which is still much higher than our result. ${ }^{30}$ Haematocrit and other parameters are similar to findings in study by Tsai et.al. and Yung et.al. ${ }^{29,30}$

According to Akram A, since 2000, Bangladesh has experienced dengue fever in every year. All four serotypes have been detected, with DENV- 
3 predominance until 2002. ${ }^{24}$ Later, during the years 2013 to 2016 a recent report showed that DENV-1 and DENV-2 were the predominantly circulating serotypes in 3 major cities in Bangladesh, including Dhaka. ${ }^{31}$ Akram A has suggested that as DENV-1 and DENV-2 have been in circulation for more than a decade, thus, a large portion of the country's population might be immune to serotypes DENV-1, DENV-2 or both; however, they are at risk of developing severe dengue infection by DENV-3 or DENV4. ${ }^{24}$ Thus, the high frequency of severe dengue cases in 2018 and 2019 correlates with the prevalence of serotype DENV- 3. ${ }^{32}$ There have been studies suggesting differences of symptoms, signs, and laboratory findings across different serotypes of dengue, without any significant differences in outcomes. ${ }^{29,33}$ After reviewing the current opinions, and recent findings, it can be deduced that DENV-3 serotype has re-emerged in Bangladesh. Thus, not only the epidemiological traits, also the clinical features have also become largely different from what the clinicians have seen for the last decade or more. Therefore, for the clinicians, a source of reference should be present regarding the currently found clinical features. This study hopefully may function as that source of reference. Moreover, according to different researchers, including Suppiah et.al. and Yung et.al., severity of disease varies among the different serotypes, and so knowing the serotype early in the course of the disease may help in predicting the severity. 30,34

Cousins $\mathrm{S}$ reported in the "Lancet Infectious Diseases Journal' that the dengue picture in Bangladesh is being further complicated by management problems such as, understaffed public hospitals in urban areas, as urban health is sorely neglected in Bangladesh, although the country boasts strong rural health system. ${ }^{28}$ The policymakers must be aware of the true situation. As, dengue is a arthropod borne viral infection, no amount of clinical management, or curative treatment will be enough to save the vast and one of the densest population like ours, without proper preventive measures, and adequate vector control.

\section{Conclusion}

To conclude it can be predicted that dengue is likely continue to constitute a serious public health problem for Bangladesh, as Mutsuddy et.al have suggested. ${ }^{13}$ The changing disease pattern should be clearly understood and constant monitoring is needed. From the policy and management level, steps should be taken up to prevent the disease.

\section{Limitations of the study}

For time and monetary constraints, only a few number of patients were enrolled in the study. Serotyping of dengue virus could not be done for the same reasons.

\section{Funding: Self-funded by the authors. Conflict of interest: None. \\ References}

1. Farhana R, Awatef KF, Khanum H, Akter T. Prevalence of dengue fevers among the patients of different economic status attended at local hospital in Dhaka. Bangladesh Journal of Zoology. 2015 May $14 ; 42(2): 161-8$.

2. Malavige GN, Fernando S, Fernando DJ, Seneviratne SL. Dengue viral infections. Postgrad Med J. 2004 Oct 1;80(948):588-601.

3. Mahmood BAI, Mahmood SAI. Emergence of Dengue in Bangladesh a major international public health concern in recent years. Journal of Environmental Research and Management. 2011;2(3):35-41.

4. Banu S, Hu W, Hurst C, Guo Y, Islam MZ, Tong S. Space-time clusters of dengue fever in Bangladesh. Tropical Medicine \& International Health. 2012 Sep 1;17(9):1086-91.

5. Rahman M, Rahman K, Siddque AK, Shoma S, Kamal AHM, Ali KS, et al. First Outbreak of Dengue Hemorrhagic Fever, Bangladesh. Emerg Infect Dis. 2002 Jul;8(7):738-40.

6. Sultana N, Biswas SK, Sultan T, Ahmed S, Hossain $Z$, Chowdhury R. Seroprevalence of Dengue Fever in Chittagong, Bangladesh. Chattagram Maa-O-Shishu Hospital Medical College Journal. 2013 Jun 28;12(1):38-40.

7. Faruque LI, Zaman RU, Alamgir ASM, Gurley ES, Haque R, Rahman M, et al. Hospital-Based Prevalence of Malaria and Dengue in Febrile Patients in Bangladesh. Am J Trop Med Hyg. 2012 Jan 1;86(1):58-64.

8. Azad A. Dengue on the rise. Dhaka Tribune [Internet]. 2016 Oct 12 [cited 2016 Nov 2]; Available from: http:/ /archive.dhakatribune.com/bangladesh/2015/oct/ 12 /dengue-rise 
9. Palma P. Dengue strikes early. The Daily Star [Internet]. 2016 Jul 19 [cited 2016 Nov 4]; Available from: http: / / www.thedailystar.net/frontpage/ dengue-strikes-early-1255999

10. Correspondent at BDNews24.com S, bdnews24.com. ডেঙ্গু: নতুন আক্রান্ত ১৭১২ জন (Dengue: Newly contracted 1712) [Internet]. BDNews24. 2019 [cited 2019 Oct 27]. Available from: https://bangla.bdnews24.com/ bangladesh/article1650032.bdnews

11. CNN SD and SP. Bangladesh hit by worst dengue outbreak on record [Internet]. CNN. [cited 2019 Oct 27]. Available from: https://www.cnn.com/2019/ 07/30/asia/bangladesh-dengue-outbreak-hnk-intl/ index.html

12. Center for Disease Control (CDC), DGHS. Bangladesh Dengue Situation Health Bulletin 2019 Volume: 3. Dhaka: Directorate General of Health Services (DGHS); 2019 Aug p. 1. Report No.: Volume 3.

13. Mutsuddy P, Tahmina Jhora S, Shamsuzzaman AKM, Kaisar SMG, Khan MNA. Dengue Situation in Bangladesh: An Epidemiological Shift in terms of Morbidity and Mortality [Internet]. Canadian Journal of Infectious Diseases and Medical Microbiology. 2019 [cited 2019 Oct 27]. Available from: https:// www.hindawi.com/journals / cjidmm/2019/ 3516284/

14. Mustafa MS, Rasotgi V, Jain S, Gupta V. Discovery of fifth serotype of dengue virus (DENV-5): A new public health dilemma in dengue control. Med $\mathrm{J}$ Armed Forces India. 2015 Jan;71(1):67-70.

15. Rigau-Pérez JG. The early use of break-bone fever (Quebranta huesos, 1771) and dengue (1801) in Spanish. Am J Trop Med Hyg. 1998 Aug 1;59(2):2724.

16. Clarke T. Dengue virus: Break-bone fever. Nature. 2002 Apr 18;416(6882):672-4.

17. Halstead SB. Dengue. The Lancet. 2007;370(9599): 1644-1652.

18. Schwartz E, Mendelson E, Sidi Y. Dengue fever among travelers. The American journal of medicine. 1996;101(5):516-520.

19. Sharp T, Wallace M, Hayes C, Sanchez J, DeFraites $\mathrm{R}$, Arthur R, et al. Dengue fever in U.S. troops during Operation Restore Hope, Somalia, 1992-1993. Am J Trop Med Hyg. 1995 1995;53(1):89-94.

20. Cobra C, Rigau-Pérez JG, Kuno G, Vomdam V. Symptoms of Dengue Fever in Relation to Host Immunologic Response and Virus Serotype, Puerto Rico, 1990-1991. Am J Epidemiol. 1995 Dec $1 ; 142(11): 1204-11$.

21. Trofa AF, DeFraites RF, Smoak BL, Kanesa-thasan N, King AD, Burrous JM, et al. Dengue fever in US military personnel in Haiti. Jama. 1997;277(19):1546-1548.
22. Potts JA, Rothman AL. Clinical and laboratory features that distinguish dengue from other febrile illnesses in endemic populations. Tropical Medicine \& International Health. 2008 Nov 1;13(11):1328-40.

23. Kalayanarooj S, Vaughn DW, Nimmannitya S, Green S, Suntayakorn S, Kunentrasai N, et al. Early Clinical and Laboratory Indicators of Acute Dengue Illness. J Infect Dis. 1997 Aug 1;176(2):313-21.

24. Akram A. Alarming Turn of Dengue Fever in Dhaka City in 2019. Bangladesh Journal of Infectious Diseases. 2019 Aug 17;6(1):1-2.

25. Amin MA. Dengue comes with changed symptoms. Daily Sun [Internet]. [cited 2019 Oct 28]; Available from: https://www.daily-sun.com/printversion/ details / 411139 / Dengue-comes-with-changedsymptoms

26. National Malalria Elimination and Aedes Transmitted Disease Control Division, Directorate General of Health Services (DGHS). Pocket Guideline for Dengue Case Management July 2019. 1st ed. Dhaka: Directorate General of Health Services (DGHS); 2019.

27. Manthalkar PS, Peerapur BV. Demographic and clinical profile of patients infected with dengue virus serotypes 1, 2, and 3 in North Karnataka. Journal of Natural Science, Biology and Medicine. 2019 Jul $1 ; 10(2): 144$.

28. Cousins S. Dengue rises in Bangladesh. The Lancet Infectious Diseases. 2019 Feb 1;19(2):138.

29. Tsai JJ, Chan KS, Chang JS, Chang K, Lin CC, Huang $\mathrm{JH}$, et al. Effect of serotypes on clinical manifestations of dengue fever in adults. J Microbiol Immunol Infect. 2009 Dec;42(6):471-8.

30. Yung C-F, Lee K-S, Thein T-L, Tan L-K, Gan VC, Wong JGX, et al. Dengue Serotype-Specific Differences in Clinical Manifestation, Laboratory Parameters and Risk of Severe Disease in Adults, Singapore. Am J Trop Med Hyg. 2015 May 6;92(5):999-1005.

31. Muraduzzaman AKM, Alam AN, Sultana S, Siddiqua M, Khan MH, Akram A, et al. Circulating dengue virus serotypes in Bangladesh from 2013 to 2016. Virusdisease. 2018 Sep;29(3):303-7.

32. Shirin T, Muraduzzaman AKM, Alam AN, Sultana S, Siddiqua M, Khan MH, et al. Largest dengue outbreak of the decade with high fatality may be due to reemergence of DEN-3 serotype in Dhaka, Bangladesh, necessitating immediate public health attention. New Microbes New Infect. 2019 May;29:100511.

33. Balmaseda A, Hammond SN, Pérez L, Tellez Y, Saborio SI, Mercado JC, et al. Serotype-specific differences in clinical manifestations of dengue. Am J Trop Med Hyg. 2006 Mar;74(3):449-56.

34. Suppiah J, Ching S-M, Amin-Nordin S, Mat-Nor L-A, Ahmad-Najimudin N-A, Low GK-K, et al. Clinical manifestations of dengue in relation to dengue serotype and genotype in Malaysia: A retrospective observational study. PLOS Neglected Tropical Diseases. 2018 Sep 18;12(9):e0006817. 